\title{
Respuesta a los comentaristas
}

\author{
Answer to the commentators
}

Mario Rovere

$\mathrm{L}$ os comentarios de estimados y respetados amigos y colegas, como Françoise Barten, Jairnilson Silva Paim, Oscar Feo y Eleonor Minho Conill, constituyen una respuesta a la razonable duda de escribir y un estímulo para animarse frente a la osadía que supone proponer un texto con un tema sobre el que parece que ya poco o nada se podía decir.

Las críticas resaltan una base, de acuerdo con el planteo, y permiten avanzar, ellas casi funcionan como sustrato o motor que ayuda a ir más allá porque impulsan a plantear nuevos interrogantes, los cuales pueden hacer que quien los lea se sienta más invitado aun a ampliar el desafío que conlleva.

En un análisis post scriptum de nuestro documento, resulta necesario precisar que el texto presentado a consideración y a debate puede producir una cierta incomodidad por el uso y abuso de preguntas, una opción intencional que requiere una explicación. Como todo texto tiene una historia, este caso tuvo su origen en la necesidad de colocar a la propia atención primaria de salud (APS) como un objeto de investigación y de estudio.

Cuando se decide tomar un concepto tan familiar y naturalizado y en parte idealizado como objeto de estudio la tarea de investigar resulta más ardua y se vuelve particularmente complicado lograr esa cierta distancia y ese extrańamiento, necesarios para lograr desnaturalizarlo y más aun desidealizarlo. Esto genera - como si de una autopsia, o en este caso una biopsia - un cierto grado de violencia simbólica imprescindible para forzar al objeto a que 'revele sus secretos'.

En el mismo sentido de desidealización, los comentarios de Jairnilson y de Eleonor se extienden hasta el propio Sistema Único de Salud (SUS) de Brasil, al que luego de años de preservarlo por fuera de los debates parece hoy necesario poner a consideración y en discusión, muy especialmente por parte de quienes lo defienden.

La conformación de este texto-herramienta, que ha ido mutando a lo largo de los tres años de trabajo, nos sirvió para la primera fase de una investigación específica en Argentina, fue luego compartido con equipos de otros países y regiones y se constató que sus preguntas podrían resultar vigentes en otros territorios, lo que parece extenderse a nuestros comentaristas, los cuales extienden sus reflexiones hasta formas concretas como la APS circula en sus propios países y experiencias más conocidas.

Otra dimensión del texto imprescindible para lograr un efecto de desidealización es apelar a la larga historia de experiencias y de intervenciones sanitarias por fuera de los hospitales que se registran desde el siglo 18, que también resultan rescatadas por los presentes comentaristas ya que permiten desmitificar y relativizar el carácter fundacional que se pretende conferir a la Conferencia de Alma Ata en donde ni siquiera, por lo que parece, se acuñó u originó el término APS. Una operación difícil si además, como en nuestro caso, no se intenta reducir la importancia de esta reunión, 
considerada un hito en la lenta y fatigosa construcción de un cierto consenso internacional por la equidad.

En este sentido, los cuatro comentaristas parecen no solo acordar sino que ańaden jugosos datos que ayudan a dimensionar la rica historia sanitaria que precede a Alma Ata mucha de la cual ha sido olvidada, quizás intencionadamente siguiendo la famosa frase de Barthés, quien más ayudó a prevenir el uso político de los mitos "las cosas tienden a perder la memoria [intencionalmente agregaríamos] que alguna vez fueron hechas".

El debate que se instala precozmente en América Latina tuvo diferentes planos y utilizó como punto de apoyo, para hacer palanca, diferentes críticas y contradicciones: 'demasiado simple', 'más primitivo que primario', 'unos pobres servicios para los pobres', etc.

Sin embargo, lo más delicado resulta del alto grado de indefinición del concepto que no solo permitió su libre circulación en políticas de diferente y hasta opuesto signo político, sino que además pudo ser absorbido sin rubor por las dictaduras militares que predominaban en América Latina, justamente cuando la reunión de Alma Ata estaba teniendo lugar.

Como trabajar entonces sobre una lectura crítica tan imprescindible como penosa, entendiendo que ella no consiste en separar lo bueno de lo malo, lo que parece más bien el territorio de la moral, sino en la laboriosa tarea de trabajar las contradicciones y encontrar dispositivos valorativamente positivos y propositivamente fértiles en contextos que parecen per se negativos y, a la inversa, identificar lo negativo en lo que en la ausencia de crítica aparece como intrínsecamente valorada. Esto es imprescindible porque millones de trabajadores de salud en el mundo se desempeñan 'a la intemperie' afuera de los espacios protectores de los grandes servicios de salud, muchas veces con escasa calificación, sin oportunidades de capacitación y con escasa o nula valoración y es a ellos y a ellas a quienes menos ayuda el análisis plano y exento de contradicciones.

Por otra parte, este inmenso caudal de experiencias apenas a encuadrarse en calificaciones académicas y contradicciones dicotómicas, que parecen más útiles para reuniones internacionales que para hacer madurar prácticas adecuadas a las múltiples realidades geográfica, cultural e históricamente situadas.
Así, el camino deductivo desde los principios a las prácticas parece menos fértil que el inverso, lo cual permite cierto grado de abstracción y teorización a partir de la multiplicidad de las prácticas creadas e inventadas en el que probablemente resulte hasta hoy el más desestructurado escenario del proceso salud-enfermedadatención. Es por ello que a pesar de orígenes y simpatías compartidas, nos apartamos del par dicotómico APS selectiva y APS comprensiva o integral, como si en esta díada pudieran caber todas las contradicciones y tensiones del campo.

Básicamente porque esa contradicción la instalaron quienes en los tiempos de la revolución conservadora de Reagan y Thatcher y desde su enorme caudal de experiencias colonialistas quisieron arrinconar el avance que la APS conllevaba; proponiendo una lucha a la defensiva, tratando de imponer el creciente stock de dispositivos tecnológicos ingeniosos que desde hace más de un siglo son imaginados para neutralizar los efectos más visibles y cuestionados de un modo de producción que no puede dejar de producir inequidad, crisis cíclicas, injusticia social, nuevas y renovadas amenazas a la salud mundial y deterioro ambiental.

Para no defraudar el carácter de debate requerido por la Revista Saúde em Debate y concentrándonos en aquellos párrafos que invitan más a una polémica, resalto la frase de Jairnilson, la cual combina la duda razonable sobre que la izquierda haya sido o permanezca crítica respecto a la APS: "Não tenho a certeza de que as esquerdas latino-americanas desacreditem no potencial da APS".

Tampoco tengo la certeza, pero señalo que trabajos como el mencionado de Mario Testa respecto a la razonable duda sobre el posible carácter de atención primitiva de la APS operan como un enunciado que se difundió como un reguero de pólvora recogiendo no solo evidencias, sino además un sentimiento crítico de muchos trabajadores de salud.

En el mismo sentido opera la recuperación que hace Eleonor: "É interessante lembrar o título provocativo 'Community medicine under imperialism: a new medical policy?' de um artigo publicado por Jaime Breilh (1979)".

No puedo en este sentido dejar de mencionar en la esfera internacional las dificultades históricas de 
encontrar bases de dialogo y articulación concreta entre 'la Medicina Social' y el 'Movimiento por la Salud de los Pueblos' (PHM). Por otro lado, circula cierta sensación de que aun entre los países que han ido más lejos en la última década enfrentando el Consenso de Washington pocos se han caracterizado por diferencias transformadoras relevantes en sus sistemas de salud.

Quizás sea anecdótica pero significativa la situación que se generó en la propia Organización Mundial de Salud (OMS), cuando con escasos meses de diferencia en el 2008 se lanzaron los documentos sobre determinantes sociales de la salud (más conocido como Informe Marmot) y el texto "APS más necesaria que nunca”, celebrando los 30 años de Alma Ata. Ambos lanzamientos no tenían ninguna conexión ni referencia cruzada entre los documentos ni entre los equipos que lo generaron.

En el mismo sentido de aprovechar el sentido polémico del ejercicio, rescato la mención de Eleonor:

Tenho refletido sobre a necessidade de realizar uma separação analítica entre os niveis macro (formulação de políticas), o nivel meso (gestão) e o nível micro (prestação direta de serviços). Embora esses niveis estejam interrelacionados, separá-los permite identificar e compreender melhor as distintas lógicas de interação e ação social que implicam estratégias particulares de mudança.

El comentario ayuda a reflexionar sobre que ha habido cierta intencionalidad en el texto de no colocar separados estos planos o niveles, ya que, en parte, esta separación ha ayudado a la incomunicación de los cuadros técnico-políticos que operan en estos diferentes niveles y a la sensación que por lo mismo que pueden aislarse analíticamente pueden darse luchas por separado.

Se entiende que en ese sentido Jairnilson cita a Sonia Fleury, mencionando que:

A constituição de sujeitos políticos que questionem a não garantia do direito à saúde, as iniquidades e as relaçóes de subordinação poderá transformar tais questóes em antagonismos para desencadear uma açâo politica.
Nesse sentido, o antagonismo é, portanto, a parteira do sujeito, pois só pode emergir pela subversão da posição subordinada do sujeito. (FLEURY, 2009, p. 39).

Coincido fuertemente en cambio con Eleonor cuando ella señala:

Com base na revisáo de diversas reformas que ocorreram a partir desse período, formulamos uma hipótese que coincide com o quadro sintese proposto no texto, o qual fornece uma interessante representaçáo gráfica de seus principais componentes. O conteúdo desse discurso representava respostas a necessidades de ordem econômica, politica e social, mas também respondia a demandas oriundas dos próprios movimentos sociais e setoriais existentes nesse contexto. De um lado, um 'polo tecnocrático' propondo a incorporação de medidas inovadoras e de racionalização das práticas (comunidade como fundamento das necessidades de saúde, hierarquização, coordenação e integração do cuidado) e de outro, um 'polo participativo', associado a uma maior democratização dos serviços (mudanças na divisão do saber/poder com ampliação da equipe, incorporação de agentes da comunidade, acesso e controle social). $O$ estudo das diversas conjunturas ou contextos de aplicação permitiria identificar seus elementos principais, combinaçôes ou a direção predominante.

No ha sido tomado en las otras críticas y comentarios, pero quisiéramos resaltar aquí la importancia que le atribuimos al esquema final del documento con las cuatro fuerzas o tradiciones que pujan en cada escenario concreto, ya que se trata de una herramienta que nos resultó instrumentalmente útil e intenta abrir y complejizar el debate y colocarlo más allá de la dicotomía APS selectiva versus la integral o comprensiva.

Para ello, es que fue propuesto en el gráfico vectores que intentan incrementar el número de actores, lógicas y perspectivas históricas que vienen forcejeando 
sobre el campo desde hace casi dos siglos, pero que distan de ser resabios anacrónicos para continuar siendo formas ideológicas concretas como la APS se piensa.

Vemos allí: las operaciones más epidemiológicomilitares de las más diferentes formas 'brigadistas' de operar y de pensar la APS para reducción de daños; aquellas que por vocación democrática o por pura conveniencia y cálculo situacional de poder de recursos, de brechas culturales, apelan al protagonismo de las propias poblaciones; las perspectivas misionales y moralistas que se referencian en forma remota en la policía médica y buscan operar especialmente sobre las poblaciones marginales, marginadas o excluidas de las grandes ciudades como parte del proceso de aculturación o de asimilación a la cultura urbana de las capas medias y a la medicalización que desde hace muchos ańos imagina un escenario de práctica que se ha vuelto más atractivo como consecuencia de las necesidades de un mercado de trabajo en sobreoferta de profesionales de salud y, últimamente, por el descubrimiento por parte de los laboratorios medicinales y de las empresas de tecnología de las oportunidades de mercado que la APS y la extensión de cobertura conllevan.

En este sentido, es creído que el rescate realizado por Jairnilson sobre los trabajos de Cecilia Donnangelo debe ser resaltado, ya que probablemente una de las fuerzas más dinámicas que enfrentaremos en los próximos ańos provenga de una fuerte medicalización de la APS, que en caso sea rentable mostrará con qué facilidad pierde su celo por mostrarse 'selectiva'.

Tal vez por ello Oscar hace referencia a que:

Es indispensable cambiar el modelo de formación de profesionales y técnicos de la salud, hoy dirigidos a la sub especialización, y marcados por las formas cada vez más deshumanizadas y mercantilizadas de las prácticas de la salud, y pasar a un modelo de formación más integral, solidario y humano, que permita desarrollar sistemas universales de salud y nuevos modelos de atención.

Del mismo modo, Françoise menciona:

Coincido con M. R. que el momento actual demanda de una reorientación profunda en la educación de profesionales de la salud, en el abordaje de los determinantes sociales, la determinación social de la inequidad en salud.

En ambos los casos, resáltese la importancia de la formación de los equipos de salud como una forma de colocar el eje en las luchas cultural e ideológica que se darán y en parte ya se están se dando en este escenario crítico de los sistemas de salud.

En síntesis, solo nos queda agradecer a nombre propio y de un equipo de investigación con quienes hemos compartido tres ańos de intensa y apasionada búsqueda al Comité Editorial de la Revista Saude em Debate y al propio Centro Brasileiro de Estudos de Saúde (CEBES) por esta magnífica oportunidad de compartir trabajos, preocupaciones y expectativas con tantos lectores. Agradecemos también a las compañeras y los compañeros de los diferentes grupos de investigadores de América Latina, que nos ayudaron con sus críticas y sugerencias, al equipo de Argentina y a los comentaristas por sus aportes, por el afecto y por la indulgencia con el trabajo y a todos por ser aun a la distancia, compañeros de tantos años de militancia, en las mismas luchas. 